\title{
144. Large Scale Motions in Lake Biwa
}

\author{
As an Information to Paleolimnology
}

\author{
By Seiichi KANARI
}

(Comm. by Koji Hidaka, M. J. A., Oct. 12, 1974)

The problem of the current pattern and of the lake water oscillation under the effect of the earth's rotation is one of the most important topics in recent physical limnology and paleolimnology, because the earth's rotation effect apparently produces a peculier water motion which differs from a simple standing oscillation caused without any rotation effect.

As seen in many articles, the Coriolis effect had been ignored in earlier studies of the internal seiches with long periods, because of the coincidence between the observed and the calculated periods. But recently, the theoretical approaches to the effect of the earth's rotation on the internal motions caused by suddenly imposed wind stress in the rotating two-layered circular basin came to be proposed by G. T. Csanady (1967) and G. E. Birchfield (1969). By their studies, the behaviors of water motions in a stratified large circular lake (bearing the size of the Great Lakes in mind) under the effect of the earth's rotation were clarified, though the model had many unrealistic features.

The internal oscillation in Lake Biwa has also been thought to be a longitudinal standing oscillation; however, our recent study suggests the effectiveness of the earth's rotation.

In the present study, we calculated the oscillations of surface and interface elevations and velocity, numerically using a two layer model of Lake Biwa with $25 \times 62$ square meshes of $1 \mathrm{~km}$ intervals, in which the direction of $\mathrm{i}$-axis is toward $\mathrm{E} 26^{\circ} 30^{\prime} \mathrm{S}$ and $\mathrm{j}$-axis toward $\mathrm{N} 26^{\circ} 30^{\prime} \mathrm{E}$.

Linear hydrodynamic equation (1) for the equivalent volume transport rate and the equivalent elevations were integrated numerically by means of the primitive method, providing the mean depth of the interface is $17.5 \mathrm{~m}$ and the density difference between the upper and lower layer is $2.5 \times 10^{-3} \mathrm{~g} / \mathrm{cm}^{3}$, corresponding to the temperature difference of $13^{\circ} \mathrm{C}$.

In the present numerical experiments, the constant $\mathrm{NW}$-wind of $5 \mathrm{~m} / \mathrm{sec}$ was applied for 450 minutes, and the free oscillations of the interface after the cessation of the wind were treated 


$$
\left\{\begin{array}{l}
\frac{\partial V_{m}}{\partial t}+f_{v} \times V_{m}=-C_{m}^{2} \nabla_{h} \cdot \zeta_{m}+F_{m} \\
\frac{\partial \zeta_{m}}{\partial t}+\nabla_{h} \cdot V_{m}=0 .
\end{array}\right.
$$

In equation (1), $f_{v}$ denotes the vertical component of the earth's rotation vector; $V_{m}$ is the equivalent volume transport rate vector; $\zeta_{m}$ is the equivalent elevation, and $F_{m}$ is the equivalent stress vector. The modal index $m$ should be replaced by $s$ and $i$ for the barotropic and the baroclinic modes respectively.

The equivalent quantities stated above can be expressed by the linear combination of the quantities referred to the respective layers similar to the Charney's method. The equivalent wave velocity $C_{m}$ can be determined as the roots of the following Stoke's equation

$$
C_{m}^{4}-g\left(h_{1}+h_{2}\right) C_{m}^{2}+\frac{\Delta \rho}{\rho} g^{2} h_{1} h_{2}=0,
$$

where $\Delta \rho / \rho$ is the fractional density difference between the layers and $\rho$ is the mean density of the whole lake water. And $h_{1}, h_{2}$ are the thickness of the upper layer and that of the lower layer respectively.

Boundary condition at the shore line is that the flow velocity normal to the shore must vanish.

From the spectrum analysis of the calculated time series at various sampling points, we constructed the spatial patterns of oscillations of the surface and the interface elevation, including the spatial distributions of respective amplitudes and phase angles, associated with the dominant periods of oscillations. But since the results obtained from the surface seiches do not differ much from those in the case of the homogeneous lake model conducted by Imasato (1971, 1972) and the surface seiches were already discussed in detail by him, we have not intention to discuss it further here.

As seen in some papers (for example, Kanari (1970)), the observed period of the internal oscillation in real Lake Biwa often agrees well with the period calculated as a longitudinal standing oscillation in a two-layered rectangular lake by the use of the following formula in the case without the effect of the earth's rotation:

$$
T=2 L \sqrt{\rho\left(h_{1}+h_{2}\right) / \Delta \rho g h_{1} h_{2}} \text {. }
$$

Accordingly we supposed the calculated elevation patterns of the model may also be similar to the surface seiches, excluding the length of the period of oscillations. However, the spatial distribution of the phase angle and relative amplitude constructed from Fourier analysis are completely different from the patterns which were previously expected.

As shown in Fig. 1 and Fig. 2, in the case of the longest period 


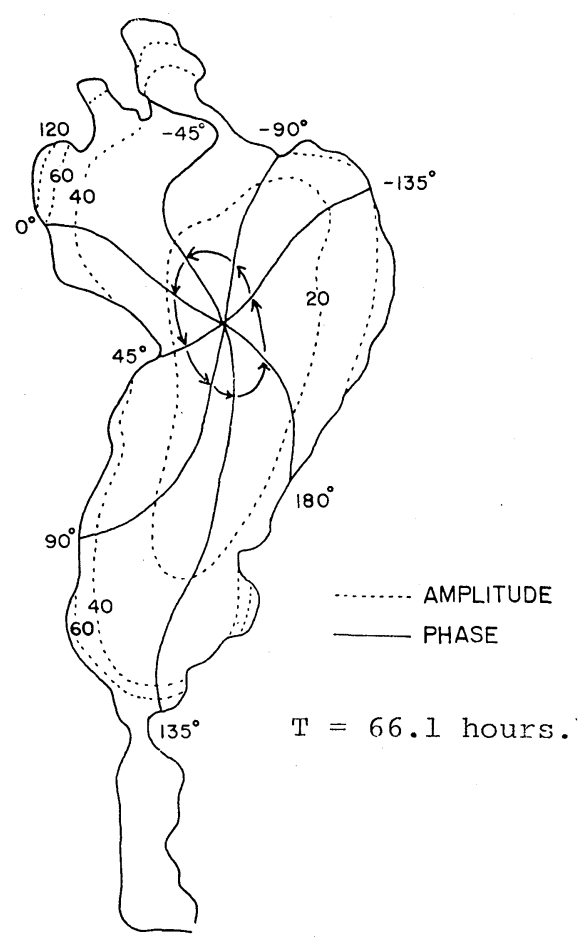

Fig. 1. Co-amplitude and co-tidal lines of the interface elevation of the period of 66.1 hours.

of 66.1 hours (the length of the period is varid in the present model only, because the length varies depending on the density structure of the lake), there always exists the phase angle difference of 180 degrees between any two opposite shore points situated at the ends of a line through an amphidromic point, and such a feature distinguishes the longest period internal oscillations in Lake Biwa from a simple longitudinal standing oscillation, such as can be seen in the surface seiches. Moreover, the phase angle increases almost linearly along the shore line anticlockwise, and this fact means that the wave of this period must be apparently a progressive one and that a wave crest (or a through) progresses along the lake shore anticlockwise with an apparent period (an apparent phase velocity is about $1.5 \mathrm{~km}$ / hr) which is adjacent to that calculated by formula (1). The large amplitude area of the wave is concentrated within the shore region and its magnitude decreases rapidly with the distance from the shore to the amphidromic point.

As the period takes the value of higher harmonics, the number of the rotating domains (accordingly the number of the amphidromic 


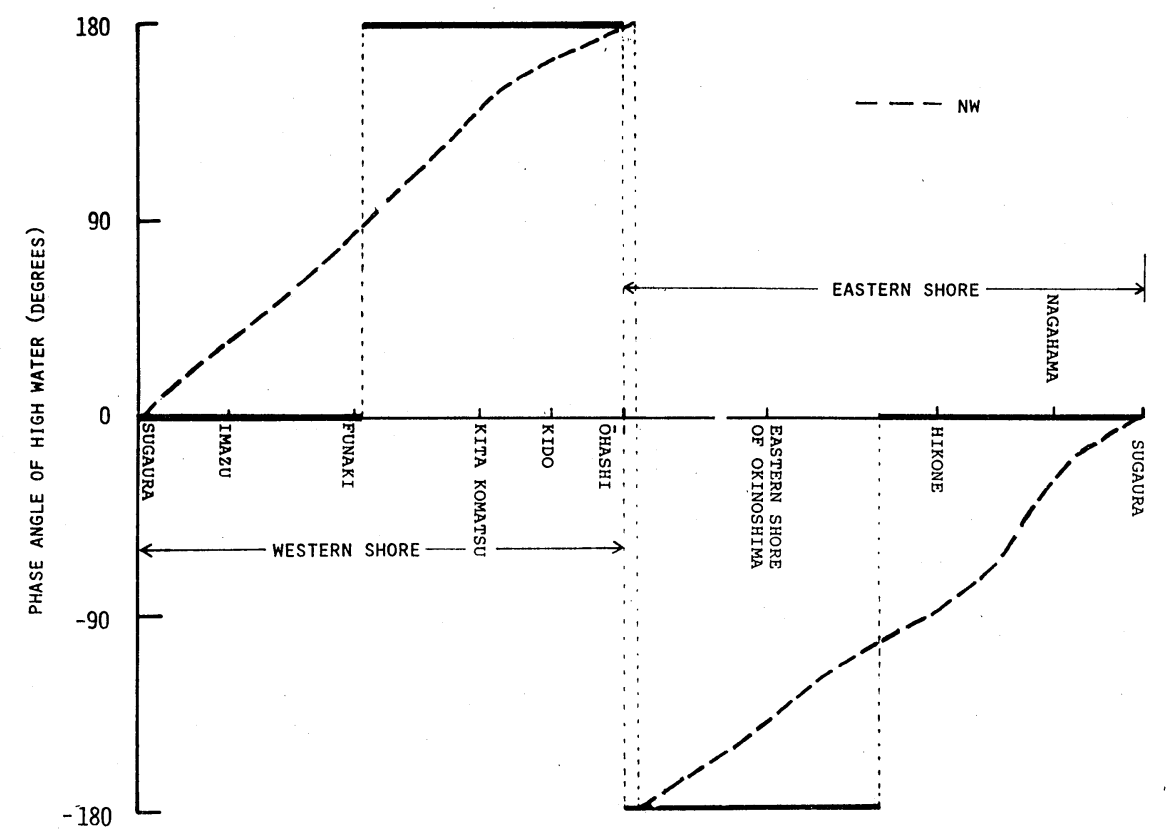

Fig. 2. Distribution of the relative high water phase of the rotating internal seiche of the period of 66.1 hours, expanded along the shore line in anticlockwise. Thick line shows the phase distribution in the case of no rotation effect.

Table I. Phase differences between Sugaura and Kido stations

\begin{tabular}{l|c|c|c}
\hline \multicolumn{1}{c|}{ Case } & $\begin{array}{c}\text { Calculated phase } \\
\text { differences (deg.) }\end{array}$ & Case & $\begin{array}{c}\text { Observed phase } \\
\text { differences (deg.) }\end{array}$ \\
\cline { 1 - 2 } NW-I & 167.0 & Sept. 25-Oct. 9, 1971 & 145.0 \\
NW-II & 150.0 & & 159.0 \\
SW & 148.0 & Aug. 5-Aug. 17, 1972 & \\
ESE & 134.0 & Mean & 152.0 \\
\hline Mean & 149.0 & & \\
\hline
\end{tabular}

points) increases until the period reaches to the inertia period of the lake (which is about 21 hours for Lake Biwa), and in the range of the period smaller than the inertia period, there apparently exists no more rotatory oscillation.

The longest period rotating internal oscillation which was identified as the lowest mode Kelvin wave in Lake Biwa, using the criterion of the existence of Kelvin waves derived from the circular model theory (Csanady, 1967), can be supported by the results obtained from observations in real Lake Biwa.

The observed phase differences at the period of dominant peak 
between Sugaura and Kido-stations show 159 degrees in the case of August 5 to 17, 1973, and 145 degrees in the case of September 25 to October 9, 1971 respectively, and they considerably differ from those which would be expected in the simple longitudinal oscillation. The observed and the calculated phase differences are shown in Table I.

For the purpose of confirming the existence of the rotating internal Kelvin waves, a daily "round cruise survey" by a high-speed survey boat with a new type Electric Bathy-thermo Graph (EBT), was carried out along the contour line at a depth of $40 \mathrm{~m}$ (seventeen fixed stations were arranged along the survey line), and temperature profiles at all the fixed stations in every five days were obtained from the records of EBT.

From the observed profiles, water temperatures at the mean thermocline depth (a depth of $15 \mathrm{~m}$ on this occasion) were expanded in Fourier series by means of 12-points harmonic analysis method. By taking the first terms in both sine and cosine series, and composing them to one, a sine term including a phase angle for the respective distributions was obtained.

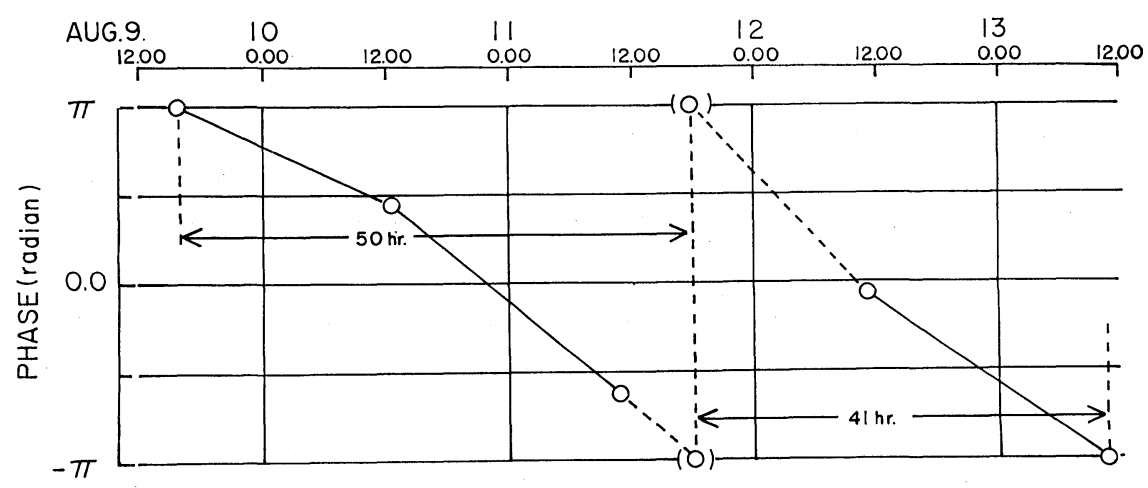

Fig. 3. Time change of the spatial phase lag in the sine functions against the station No. 1 (Sugaura), which includes two cycles of the internal waves traveling around the lake shore counterclockwise with the mean period of 45.5 hours.

Therefore, we can find the daily change of the phase angle of the sine function at every station; for example, as shown in Fig. 3, the daily change of the phase angle at the station No. 1 demonstrates that in the first cycle the phase angle decreases almost linearly from 180 to -180 degrees during 50 hours, and in the next cycle, it also decreases by the same angle during 41 hours. Of course, the change of the phase angle must be caused by the rotating internal Kelvin wave in Lake Biwa. 
Namely, the two cycles of rotation are included in the five days' observation and besides, the linear shift of the spatial phase means an anticlockwise transmission of that wave. Furthermore, its mean period is 45.5 hours, and the period coincides with that of the internal oscillations observable in Lake Biwa from July through August.

In the present study, it was confirmed that the long period internal seiches in Lawe Biwa are affected by the effect of the earth's rotation, and the resulted high water region of the interface moves along the lake shore anticlockwise with the same period as in the case of no-rotation. The current system associated with these internal seiches, of course, has a different behavior from the one with no rotation effect. Namely, the rotating internal seiches cause a quasi-geostrophic water motion in the lower layer as well as in the upper layer, which may include the large-scale cyclic circulations along the shore. These currents will execute the most principal work on the occasion of the final transportation of the suspended sediments or contaminative materials poured into the lake through the rivers, and they will control the pattern of the sedimentation in the lake basin floor. Accordingly, an effect of such currents in Old Lake Biwa must have been reflected in the deep sediment layer, and we have to take into account the existence of such flow patterns when we treat sediment cores in their paleolimnological aspect.

\section{References}

Birchfield, G. E.: Response of a circular model Great Lake to suddenly imposed wind stress. J. G. R., 74(23), 5547-5554 (1969).

Csanady, J. T.: Large-scale motion in the Great Lakes. J. G. R., 72(16), 41514162 (1967).

Imasato, N.: Study of seiche in Lake Biwa-ko. I. On the numerical calculation by Defant's method. Special Contr. Geophys. Inst. Kyoto Univ., 10, 93-103 (1970).

-: Study of seiche in Lake Biwa-ko. II. On the numerical experiment by nonlinear two-dimensional model. Contr. Geophys. Inst. Kyoto Univ., 11, 77-90 (1970).

Kanari, S.: Internal waves in Lake Biwa. I. Bull. Disast. Prevent. Res. Inst. Kyoto Univ., 19, 19-26 (1970).

-: Internal waves in Lake Biwa. II. Bull. Disast. Prevent. Res. Inst. Kyoto Univ., 22, 69-96 (1973). 